\title{
Design de Interiores Aplicado a Cenografia de Doramas
}

Lygia Menezes de Lima;

Thiago Berzoini

resumo:

Na composição cinematográfica a cenografia é usada para impactar os espectadores e contribuir para a atmosfera da história. Junto de fatores como a narrativa, o figurino, entre outros, o cenário é pensado para constituir uma estruturação do estilo de vida dos personagens. Nesse contexto, observando os doramas japoneses, é possível concluir que neles a representação visual das habitações se aproxima da vida cotidiana da sociedade na região retratada. $\mathrm{O}$ objetivo desse artigo é, através do Design de Interiores, explorar a relação do personagem nesse tipo de produção com o espaço e como esse pode reproduzir um ambiente que descreva sua personalidade, atributos, nacionalidade, entre outros fatores que compõem sua vida.

palavras-chave:

Design; Dorama; Cenografia; Personagem; Ambiência 


\title{
1 Introdução
}

De acordo com a autora Pamela Howard em seu livro O Que é Cenografia? (2009): "A visão de mundo da cenografia revela que o espaço é o primeiro e o mais importante desafio de um cenógrafo. $\mathrm{O}$ espaço é parte do vocabulário cenográfico". Com o surgimento da televisão e a popularização da narrativa seriada que se caracteriza pelo desenrolar em interiores no século $\mathrm{XX}$, tornou-se mais comum a composição de cenários que representem ambientes internos ser utilizada através do viés naturalista, como uma forma de reprodução estética do que é real, sendo um cenário que pode ser entendido como aquele em que "cada detalhe é levado em consideração durante a criação, exigindo maior fidelidade possível a um ambiente existente no cotidiano exterior (...)" (BURLA, 2004, p. 136).

Nesse contexto surgiram séries televisivas cujo enredo se desenrolava quase completamente em uma composição de interior, por exemplo, as sitcons - abreviação de "situation comedy", comédia de situação, como esclarece Cassio S. Carlos (2006, p. 14). No artigo (2014) sobre novas modalidades de sitcom e o fenômeno confessional a mestranda em Comunicação e Semiótica na PUC/SP Fernanda Manzo Ceretta apresentou uma definição objetiva do que é Sitcom televisivo com uma citação de Elizabeth Bastos Duarte, professora da Universidade Federal de Santa Maria e pesquisadora de televisão.

\begin{abstract}
"Trata-se de histórias curtas e independentes, com personagens fixos, que utilizam como quadro de referência o mundo exterior próprio de um determinado núcleo social, familiar ou profissional, colocando em cena a vida e/ou as atividades profissionais das pessoas pertencentes a esse grupo. Esses programas não costumam ter data de encerramento pré-definida, podendo estender-se, no tempo, enquanto houver audiência e, consequentemente, patrocínio e/ou publicidade" (DUARTE apud CERETTA, 2008, p.1).
\end{abstract}

Esse formato televisivo se tornou popular a partir dos anos 1950 com sucessos como I Love Lucy (Pugh, Carroll, Oppenheimer, Schiller; 1951) e se sucedeu nos anos seguintes com programas famosos como Bewitched (Saks; 1964), Full House (Franklin; 1987), Friends (Crane, Kauffman; 1994), How I Met Your Mother (Bays, Thomas; 2005), entre outros.

Apesar do cenário ocidental ser conhecido pelo grande sucesso de sua produção de séries televisivas, o oriente também se destaca por produzir conteúdo que apesar de ser fictício, apresenta elementos do estilo de vida deles, tais como seus meios de transporte, vestimentas, tradições, cotidiano, entre outros. No Japão, a representação dessa cultura se dá através elementos geralmente direcionados ao público jovem, dentre os quais se destacam mangá ${ }^{1}$, animes ${ }^{2}$, videogames, live-action e dramas televisivos.

Uma das maneiras para que os costumes japoneses possam ser representados e recebidos pelo público na cultura pop é através das telenovelas, tradicionalmente denominadas doramas ${ }^{3}$. Diferentemente do modelo brasileiro de telenovelas, os doramas ou j-dramas, outra maneira de se referir a essas produções audiovisuais japonesas, possuem um modelo de capítulos semanais que ocupam cerca de uma hora da programação e podem apresentar continuações com novas temporadas, como ocorre nas séries americanas.

Dentre esses doramas, percebe-se que por serem destinados ao público juvenil, a maioria deles se passa no cenário escolar buscando representar os costumes dos jovens do país, porém normalmente há momentos em que essas telenovelas japonesas mostram a habitação dos personagens, geralmente com o intuito de representar certa condição social ou financeira, ou, até mesmo a relação desses jovens com seus parentes. Conforme as seguintes produções podem corroborar: Hana Yori Dango (Yoko

\footnotetext{
${ }^{1}$ Nome característico de histórias em quadrinhos japonesas, e esse por ser um substantivo em japonês, não possui singular ou plural, sendo entendido apenas pelo contexto.

${ }^{2}$ Nome atribuído internacionalmente à desenhos animados produzidos no Japão, porém para os japoneses, o termo refere-se a todas as produções de animação, sejam elas nacionais ou estrangeiras.

${ }^{3}$ Definição generalizada de telenovelas orientais. Podem essas ser japonesas, chinesas, coreanas ou tailandesas, e quando são adaptações de mangá ou animes, podem ser chamadas de live-action.
} 
Kamio; 2005), Itazura Na Kiss (Yuiko Miura; 2013), Death Note (Tsudumi Ohba; 2015), e Anohana (Mari Okada; 2015).

A escolha do tema desse artigo se dá devido ao recente contato da autora com o projeto de pesquisa "Cenografia e narrativas", onde eram exploradas temáticas do curso de Design de Interiores acerca de fatores da cenografia nas produções audiovisuais, dentre esses, pesquisas sobre o jogo de cor e luz nos cenário e como os diretores e produtores de cinema se utilizavam do recurso como forma de caracterizar a personalidade dos personagens, as circunstâncias em que o mesmo se encontra, ou até mesmo a atmosfera de uma situação específica, além de uma análise feita no decorrer da faculdade que examinava composições de filmes e séries em que o espaço não simplesmente existia, mas afetava os protagonistas diretamente, suas ações e reações emocionais. Nesse contexto esse estudo irá trazer o tema para o cenário oriental, mais especificamente para as telenovelas japonesas.

Essa decisão foi tomada baseando-se na hipótese de que é padrão as pessoas terem o mercado de hollywood como referência de histórias que se situam no cenário habitacional, porém ao tomar conhecimento dos j-dramas, foi possível perceber que, por serem direcionados para o público japonês, carregam uma profunda identidade sociocultural, que pode ser usada para conhecer melhor a população que vive no local onde ele se situa, suas crenças, tradições, hábitos e a relação deles com suas habitações. Quando se trata do mercado de entretenimento audiovisual, é comum que o brasileiro procure mais produções norte americanas do que até mesmo as nacionais, mas o mercado da cultura pop japonesa tem se expandido cada vez mais.

O consumo do Brasil desse tipo de conteúdo teve seu ápice em meados dos anos $1990 \mathrm{com}$ o aumento da demanda de animes, mas o crescimento dos serviços de Streaming nas últimas décadas facilitou o acesso das pessoas a esse conteúdo tornando-o cada vez mais presente no âmbito do entretenimento, portanto esse artigo trata-se de um tema atual que acompanha os avanços tecnológicos e a facilidade de acesso da população a produções de outros países.

O objetivo geral desse estudo é analisar a influência do design de interiores nas ações e personalidade dos protagonistas de doramas japoneses. Além disso, seu propósito específico é exemplificar como o cenário dessas telenovelas é montado para retratar a cultura, hábitos e costumes dos personagens que o habitam, analisar a relação das pessoas com o ambiente que elas vivem e como essas relações são exploradas no contexto cinematográfico, mostrar como a cenografia pode levar o público a entender fatores implícitos no enredo, além de relacionar o crescimento recente dos serviços de Streaming com maneira em que as pessoas consomem o entretenimento audiovisual proveniente de outros países.

O trabalho será desenvolvido a partir da análise de artigos científicos já publicados e da revisão bibliográfica de autores que exploram a relação do homem com o lugar ou do enredo com a cenografia, além da análise de produções audiovisuais em que o cenário influência direta ou indiretamente nos personagens. Esse apresenta um tipo de pesquisa exploratória, por ser bastante específica e resultados qualitativos, pois nela há um levantamento e coleta de dados mais subjetivos, buscando compreender e interpretar determinados comportamentos, opiniões, expectativas, sentimentos, percepções, entre outros aspectos imateriais.

\section{Considerações sobre os Doramas (J-dramas)}

Dentre os diversos doramas já produzidos, um exemplo que decorre predominantemente no contexto habitacional é a live-action Good Morning Call (Kanome, Suzuki, Obayashi, Kanda; 2016). Essa é uma adaptação televisiva de um mangá shojjo ${ }^{4}$ criado por Yue Takasuka (1997), publicado pela editora Shueisha, e que teve sua versão live-action co-produzida pela Fuji TV (Japan) e pela Netflix (mundial). A primeira temporada foi ao ar em 2016, e uma segunda temporada foi ao ar em 2017 sob o título Good Morning Call: Our Campus Days ${ }^{5}$.

Nessa telenovela japonesa a adolescente Nao Yoshikawa muda-se para seu próprio apartamento na cidade, quando seus pais voltaram ao interior para que pudessem administrar a fazenda da família. No entanto, ela logo descobre que Hisashi Uehara, um colega de escola conhecido por ter boa aparência, também está se mudando. Percebendo que eles foram enganados em alugar o mesmo

\footnotetext{
${ }^{4}$ Tipo de mangá visado para o público feminino.

${ }^{5}$ Informações retiradas de: https://en.wikipedia.org/wiki/Good_Morning_Call. Acesso em: 21/03/2019
} 
apartamento, eles concordam em se tornar companheiros de quarto, a fim de fazer o pagamento do aluguel. A história segue suas aventuras enquanto eles tentam manter sua coabitação em segredo de seus colegas, com Nao desenvolvendo sentimentos românticos por Hisashi quando ela o conhece melhor ${ }^{6}$.

Esse dorama exemplifica a questão da influência que o espaço possui nos personagens, visto que os protagonistas não possuem uma relação amistosa quando começam a morar juntos, tanto que nos primeiros capítulos do j-drama os dois discutem frequentemente e criam várias regras que facilitam a convivência, porém no decorrer da trama eles passam a demonstrar mais afeição até desenvolverem sentimentos românticos um pelo outro.

A partir da análise desse dorama é justificável considerar que o motivo de tanto atrito no início da convivência dos protagonistas possa ser o sentimento de invasão de um espaço que deveria ser só seu por uma pessoa com manias e personalidade diferentes. É possível perceber que no decorrer do tempo de convivência entre os personagens principais, eles passam a conhecer melhor um ao outro, seus hábitos, costumes e a aceitação de ambos do fato de que o espaço era agora "deles", contribuiu para que fosse construído um vínculo entre os dois.

Nessa observação nota-se que os produtores do dorama utilizam-se da composição do interior no apartamento para representar a evolução do relacionamento de Nao Yoshikawa e Hisashi Uehara. Isso pode ser percebido no fato de que no decorrer da trama objetos característicos de cada personagens encontram-se pelo apartamento, mostrando que eles estão cada vez mais familiarizados com o ambiente que eles foram inicialmente "forçados" a habitar.

Nesse contexto e usando como base a análise de Good Morning Call, esse artigo irá apresentar como a composição do interior de um ambiente pode ser explorada como um fator determinante para diferentes comportamentos, sentimentos, hábitos, entre outras questões subjetivas.

\subsection{Análise de Good Morning Call}

Como dito anteriormente, o j-drama Good Morning Call se difere da maioria considerando que esses geralmente se situam no contexto escolar, sendo que quando mostram a habitação dos personagens, é normalmente apenas com o intuito de mostrar melhor quem são os personagens, a história por trás de sua personalidade, ou o relacionamento com seus responsáveis, ou seja, suas casas não possuem relação direta com os protagonistas, servindo apenas como plano de fundo para suas vidas e o enredo principal se passa na escola.

Nesse contexto, ao analisá-lo é possível perceber que a produção cenográfica dessa telenovela japonesa apresenta um design clean e funcional presente em muitos interiores residenciais do Japão, escolha que pode ser entendida como uma maneira de mostrar ao público que, apesar de morarem sozinhos, ambos ainda são jovens estudantes, não é uma casa de família, portanto eles não possuem muita coisa, e sim se prendem ao que é estritamente necessário e deixar implícito que a área comum do apartamento é um espaço neutro, sendo que quando ambos começam a se adaptar ao local e deixam de ser estranhos um para o outro, essa área de convívio começa a conter elementos da personalidade de cada um deles. Seguem abaixo a imagem 1 (um) que consiste na sala no início do drama e a imagem 2 (dois) que mostra o mesmo ambiente no decorrer do dorama.

\footnotetext{
${ }^{6}$ No original "Teenager Nao Yoshikawa has moved into her own 2DK apartment in the city as her parents have returned to the country to manage the family farm. However, she soon discovers that Hisashi Uehara, a goodlooking classmate, is also moving in. Realizing that they have been scammed into renting the same apartment, they agree to become roommates in order to make the rental payment. The story follows their adventures as they try to keep their cohabitation a secret from their classmates, with Nao developing romantic feelings for Hisashi as she gets to know him better." (tradução autoral). Trecho retirado de:

https://en.wikipedia.org/wiki/Good_Morning_Call. Acesso em: 21 mar. 2019
} 


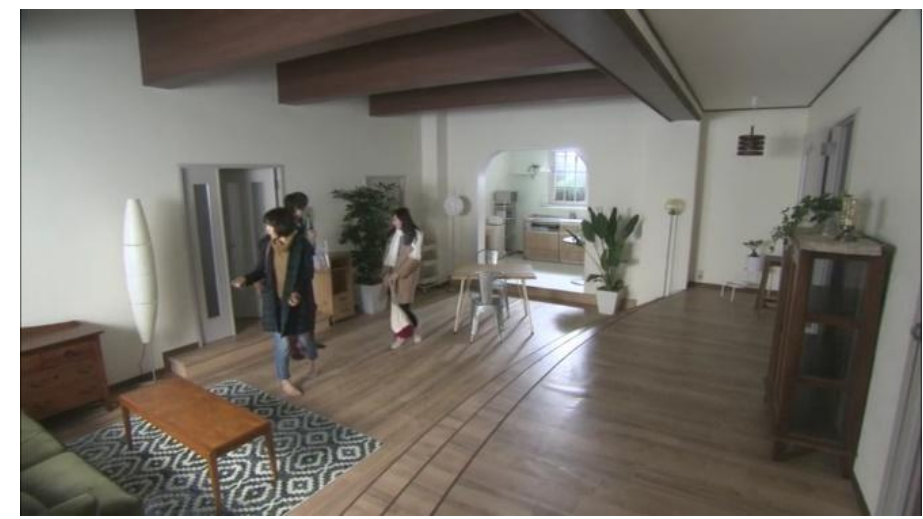

Imagem 1 - Cenário no início de Good Morning Call. Fonte: http://aitoda.blogspot.com/2020/02/haruka-fukuhara-lot-of-this-and-

thats.html acessado em 21/08/2019

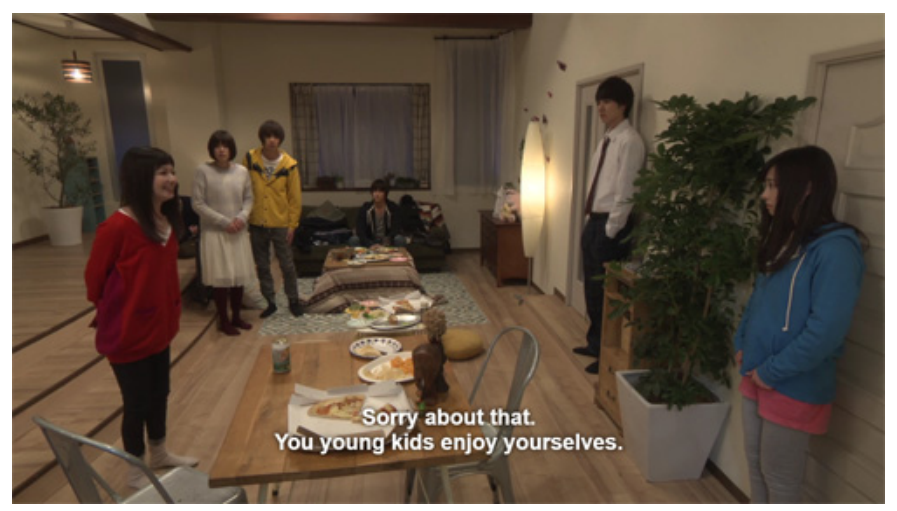

Imagem 2 - Cenário no decorrer de Good Morning Call. Fonte: https://www.tumblr.com/search/s\%3Agood\%20morning\%20call acessado em 21/08/2019

Apesar disso, o uso do cenário habitacional como plano de fundo para a composição dos personagens não se perde nessa imparcialidade do local. Como a área comum do apartamento foi representada como um espaço neutro, nos quartos de cada um dos personagens nota-se a divergência da personalidade de cada um. O quarto do protagonista masculino é representado apenas com os mobiliários básicos, tons de azul e marrom, apresentando uma atmosfera mais séria, enquanto o quarto da protagonista feminina é composto com móveis em tons de rosa, amarelo e azul claros, além de diversos adornos e pelúcias, mostrando uma atmosfera mais divertida e descontraída. As imagens 3 (três) e 4 (quatro) abaixo mostram o quarto de cada um deles na segunda temporada, nessa eles não moram mais juntos, mas essas retratam claramente o estilo de cada um. 

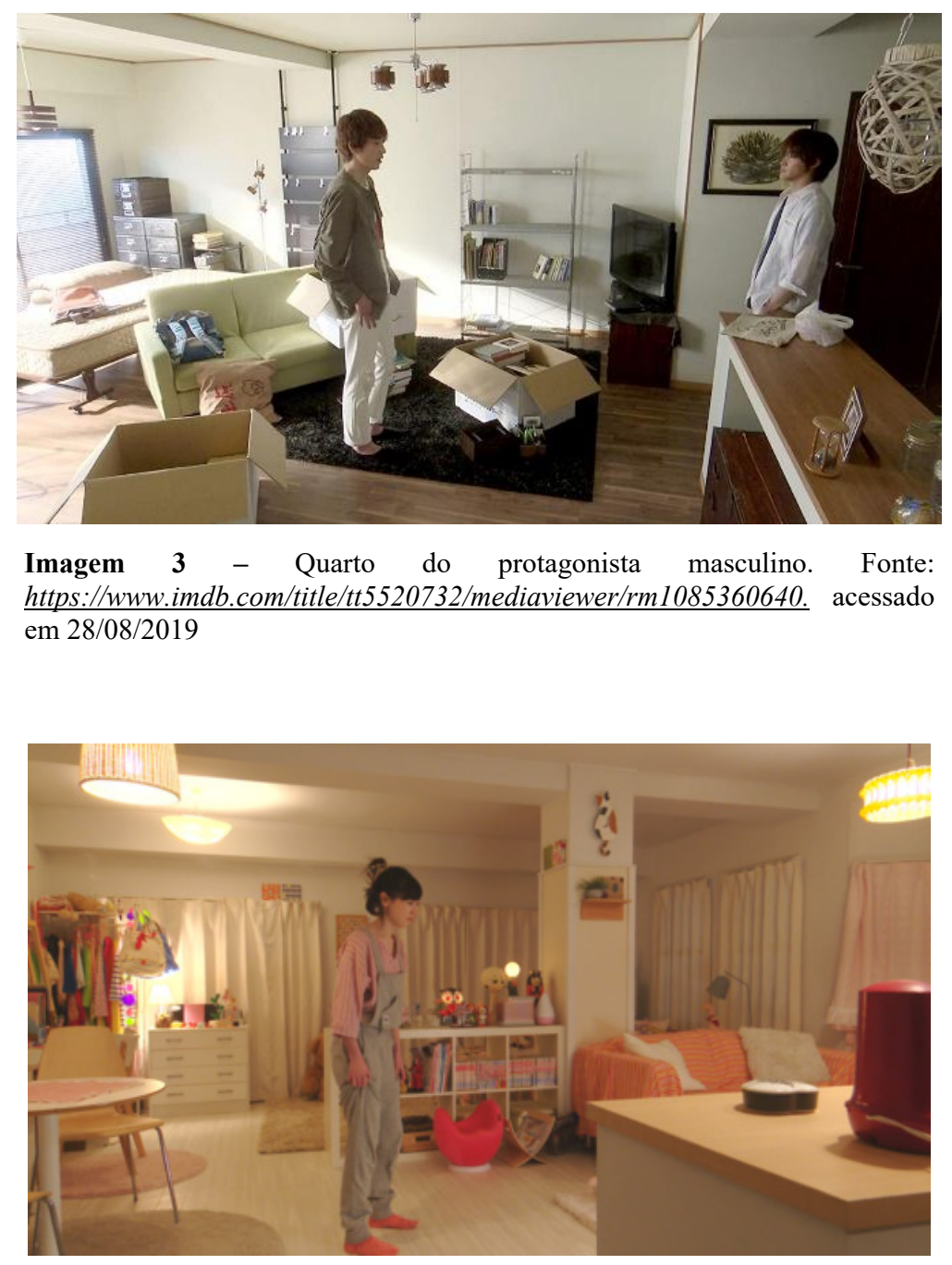

Imagem 4 - Quarto da protagonista feminina. Fonte: https://br.pinterest.com/pin/613756255449913971/acessado em 28/08/2019

Nota- se que pelo fato de que os protagonistas tinham que agir com naturalidade na escola para que os outros não desconfiassem que eles moravam juntos, os produtores exploram mais o cenário de convívio do apartamento, desenvolvendo a relação entre eles naquele ambiente, tornando-o cenário principal da telenovela. É possível perceber que essa escolha dos produtores como ambientação interior reflete diretamente no enredo, visto que pode-se observar que praticamente todos os objetos vistos em cena são utilizados pelos protagonistas em algum momento do enredo, alguns exemplos são: a mesa de centro, que a perspectiva ocidental geralmente nos leva a concluir que é apenas um móvel de apoio, nessa série televisiva eles a usam com um tipo de cobertor com aquecedor elétrico e a usam como mesa de lanches rápidos quando comem algo entre refeições; a pequena escada de apenas três degraus que ,invés de terem um mobiliário específico para o apoio da televisão, eles a deixam sobre um desses degraus; além do fato de que eles são mostrados lavando a louça, abrindo a geladeira, colocando o casaco no armário, e realizando outras atividades cotidianas.

Em termos de produção cenográfica, essa interação dos personagens com o cenário se aproxima bem do viés naturalista, que a na época doutoranda em psicologia clínica (PUC/SP) Silvia Balestreri Nunes em sua tese "Boal e Bene: contaminações para um teatro menor" (2004, p.72) esclareceu: "Digamos que nas peças consideradas "naturalistas", se pretendia aproximar a cena o máximo possível da realidade cotidiana ou do cotidiano e da época em que se passa a peça: objetos, figurinos, diálogos, gestual dos atores".

Nesse contexto, uma definição de cenografia que pode se dizer que se aproxima do que é o naturalismo é a citação da cenógrafa israelense Tali Itzhaki presente na obra "O que é cenografia?" de 
Pamela Howard (2009), "A cenografia é em essência: um ser humano em um espaço humano" (ITZHAKI apud HOWARD, 2009, p.21). Essa "humanização" pode ser percebida no princípio de que os autores dessas telenovelas geralmente trabalham com o intuito de que o público sinta uma aproximação do que se pode ver no cenário, com o que ele conhece do cotidiano, visto que os j-dramas normalmente são produzidos visando audiência do público japonês.

\begin{abstract}
"Tudo neste cinema caminha em direção ao controle total da realidade criada pelas imagens - tudo composto, cronometrado e previsto. Ao mesmo tempo, tudo aponta para a invisibilidade dos meios de produção desta realidade. Em todos os níveis, a palavra de ordem é "parecer verdadeiro"; montar um sistema de representação que procura anular a sua presença como trabalho de representação" (XAVIER, Ismail, 2005).
\end{abstract}

Essa representação da realidade pode causar uma sensação de semelhança ao público asiático mais do que ao ocidental, isso provavelmente ocorre pelo fato de que a cultura pop japonesa é produzida buscando atingir os jovens do próprio país, portando é comum que retrate a visão japonesa de seus próprios costumes. Em Good Morning Call a cultura japonesa que é representada fora da Ásia, como, por exemplo, o uso de quimonos e visitas a templos pode ser percebida quando os protagonistas visitam locais típicos de tais atividades, mas não está presente do cotidiano deles. No cenário habitacional dessa trama específica não há adornos japoneses espalhados ou árvores típicas orientais pelo apartamento, a representação dessa cultura é bem mais sutil, visto que é composto propositalmente para que as pessoas que vivem no Japão entendam o contexto da história imediatamente.

\title{
3 Design de Interiores como representação de diferenças sociais e econômicas
}

Essa corrente naturalista pode ser explorada pelos autores dessas produções audiovisuais para que o público obtenha informações visuais rápidas quanto às características de cada personagem, de onde vieram, o tempo que se passa a história e a vida de cada um de maneira implícita na trama, contribuindo, justo de fatores como o roteiro e os figurinos, para o entendimento rápido da cena pelo público.

\begin{abstract}
"O teste para o cenógrafo é ver se toda a preparação ficou em equilíbrio e se os espectadores entenderam a visão e a intenção da produção. Há alguns passos muito práticos a serem seguidos. Se os espectadores não conseguem ver, não conseguirão escutar. (...). Se o público não consegue ver nem ouvir, perderá a concentração e, em pouco tempo, ficará inquieto. (...). Desde o início, a área cênica precisa ser planejada do ponto de vista dos espectadores" (HOWARD, 2009, p.229).
\end{abstract}

No caso dos doramas japoneses é comum que essa mensagem rápida que o público recebe devido à ambientação interior seja referente a algum tipo de questão financeira, social ou de parentesco. Como dito anteriormente, os j-dramas são direcionados para o público jovem japonês e comumente buscam trazer essa representação do jovem no país, mas assim como o ocidente tem certos estereótipos sobre o estilo de vida no Japão, o próprio também possui os seus sobre as diferentes condições financeiras do próprio país.

Um exemplo disso, é a live-action Hanna Yori Dango (Yoko Kamio; 2005). Essa é uma adaptação televisiva de um mangá homônimo criado por Yoko Kamio (1992), publicado pela editora Shueisha, e que teve sua versão live-action produzida por Setoguchi Katsuaki. A transmissão original foi de 21 de outubro até 16 de dezembro de 2005 através da emissora de TV TBS ${ }^{7}$.

\footnotetext{
${ }^{7}$ Informações retiradas de: https://en.wikipedia.org/wiki/Hana_Yori_Dango_(TV_series). Acesso: 29 abr. 2019.
} 
O enredo do drama consiste em Makino Tsukushi, personagem principal, é uma adolescente de uma família pobre que, apesar das dificuldades financeiras, conseguiu ser admitida na Eitoku Gakuen, escola de pessoas extremamente ricas. Para que ela possa estudar, sua família passa, com orgulho, por muitas privações. Nessa escola, os alunos esbanjam suas vantagens financeira, porém, os que mais se destacam são um famoso grupo de quatro rapazes chamado de Flower Four, os F4 (flores no sentido de preciosos), que são os herdeiros das mais poderosas famílias do Japão. Pelo poder financeiro dos seus nomes, eles ditam as regras na escola, passando por cima até mesmo dos professores e diretores.

Nesse cenário de ostentação, tudo o que Makino Tsukushi deseja é se formar tranquilamente, sem se envolver com os outros alunos. Porém, depois de um incidente, onde ela não pôde ficar calada diante da injustiça do líder do F4, ela se torna um alvo para o grupo F4. A partir daí, sua vida nunca mais foi a mesma.

Com o passar do enredo, o líder do F4 (Tsukasa Doumyouji) se apaixona por Makino, mas ela o considera muito implicante. Aos poucos ela acaba se tornando mais próxima dos $\mathrm{F} 4$, tendo uma admiração maior por Rui Hanazawa (outro membro do F4) formando o triângulo amoroso do dorama. Então muitas coisas acontecem até ela realmente perceber que ama Doumyouji ${ }^{8}$.

O mangá é considerado o shōjo (para meninas) mais vendido no Japão e, o seu sucesso ocorreu por tratar da vida escolar e da violência estudantil de forma realista, ganhou uma versão animada em 1996 com 51 episódios, um filme de curta metragem, com as personagens em uma história paralela, e o dorama japonês em 2006. Além da telenovela japonesa, a obra ganhou também uma adaptação taiwanesa, uma coreana e recentemente o serviço de Streaming Netflix lançou uma versão chinesa nomeada "Meteor Garden" (Sharon Mao, 2018).

Esse é um dorama em que, apesar de se passar no contexto escolar, é possível ver a habitação dos protagonistas frequentemente, isso ocorre porque o foco da trama desse drama é a diferença exorbitante de condições financeiras entre eles (refletindo esses aspectos na cenografia), portanto torna-se necessário dar ênfase no local onde cada um vive para conseguir que a audiência perceba de forma clara essa divergência.

Diferente do dorama analisado anteriormente (Good Morning Call), o cenário habitacional de Hana Yori Dango representa um ambiente familiar, sendo possível perceber a identidade de cada família em suas casas. No caso da protagonista feminina, que é de origem humilde, a residência em que ela vive com seus pais é bem pequena, clara, apertada e apresenta um amontoado de coisas, reforçando a ideia de que o espaço é reduzido, mas possui grande carga emocional, carregando as memórias de sua família. Enquanto a casa do protagonista masculino é muito maior e com muitos espaços vazios, tons escuros, móveis grandes e pesados e essa atmosfera também se reflete na relação dele com sua mãe, sendo que nesse caso é a falta dela, visto que ela além de tratar o adolescente com extrema rigidez, viaja muito, e além disso, foi revelado no início da trama que ela esteve fora por seis meses e a empresa da família dele faz muitos negócios em Londres, portanto é possível apresentar a hipótese de que a casa dele representa um tipo de estereótipo da residência inglesa.

Essas duas divergências no cenário do interior das casas dos personagens principais representa um tipo de estereótipo de como seria a residência da família humilde se contrapondo com a da abastada. Isso pode ser notado porque no começo da trama, quando os personagens ainda estão sendo apresentados, mostra frequentemente a residência da protagonista feminina e em seguida a do masculino. Portanto, esses cenários foram explorados para que o público absorvesse fatores implícitos no enredo que retratam a condição financeira de cada um deles. Isso é representado na Imagens 5 (cinco), mostra uma residência humilde e 6 (seis), que representa um ambiente abastado, através dessas imagens pode se fazer uma comparação entre dois cenários divergentes do dorama Hana Yori Dango.

\footnotetext{
${ }^{8}$ Informações retiradas de: http://mundoyuki2.blogspot.com/2016/03/hana-yori-dango.html. Acesso: 29 abr. 2019.
} 


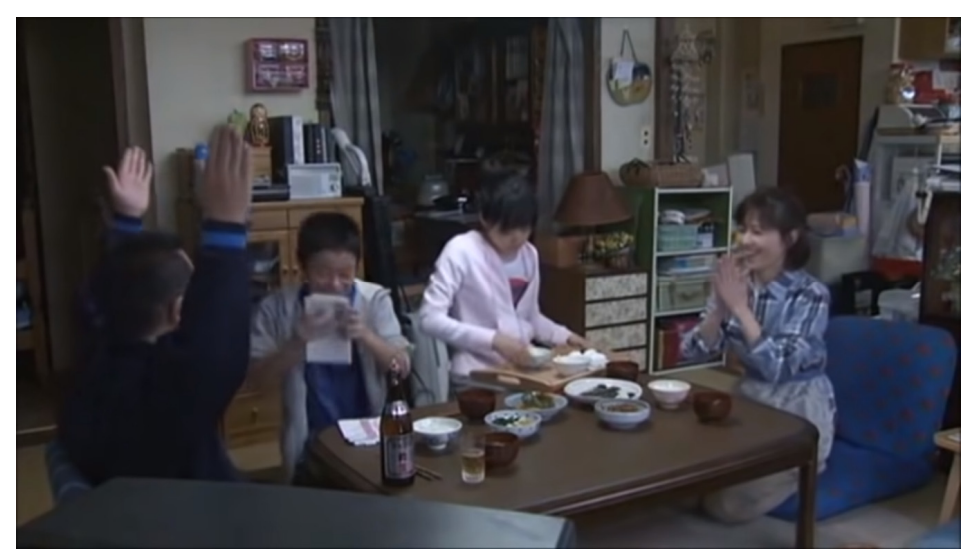

Imagem 5 - Cenário da residência humilde de Hana Yori Dango. Essa imagem é a captura de tela de um vídeo. Fonte:

https://vimeo.com/78311724 acessado em 01/09/2019

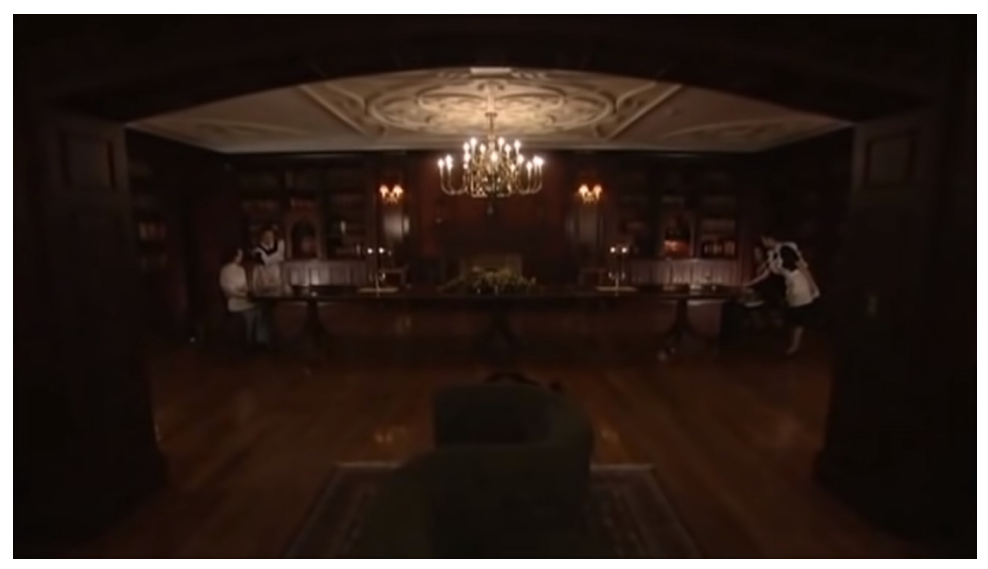

Imagem 6 - Cenário da residência abastada de Hana Yori Dango. Essa imagem é a captura de tela de um vídeo. Fonte:

https://vimeo.com/78311724 acessado em 01/09/2019

\section{Representação cenográfica de estereótipos japoneses}

A questão de a cenografia naturalista retratar elementos cenográficos com o objetivo de aproximação do real faz com que as produções busquem mostrar de maneira implícita o estilo de vida dos personagens, permitindo que o público entenda o enredo desde o princípio da trama através de recursos visuais. Para que ocorra o entendimento imediato do contexto do drama, muitas vezes as produções destacam representações sociais conhecidas no contexto em que seu público alvo se situa. Um exemplo desse padrão é o dorama mencionado anteriormente Good Morning Call, visto que nele é possível notar elementos generalizantes, como o fato de que a protagonista é mostrada como sendo uma garota sensível e feminina e em seu quarto é possível ver uma abundância da cor rosa e de pelúcia, elementos geralmente associados ao termo "feminina".

$\mathrm{Na}$ sociedade, tanto ocidental quanto oriental, o julgamento prévio pode ser visto como comum, ou seja, as pessoas costumam tirar conclusões sobre o que veem baseando-se em suas próprias referências de como as pessoas de certa nacionalidade se comportam e vivem. Apesar disso, a visão exterior do cenário japonês tem sido modificada nos últimos anos deixando de ser ligada apenas à uma cultura tradicional e adquirindo uma representação mais divertida e colorida, associada à indústria do entretenimento.

Essa generalização não é novidade no contexto das produções audiovisuais, visto que até mesmo em produções de Hollywood é possível perceber um padrão para representar asiáticos que 
muda de tempos em tempos. No livro de Reel Inequality: Hollywood Actors and Racism (2006) a socióloga Nancy Wang Yuen afirma: "Racismo, na forma de exclusão do mercado de trabalho e de papéis estereotipados, marca a indústria cinematográfica de Hollywood já desde os seus primórdios, no início dos anos 1900"?.

A representação asiática na cultura pop geralmente se dava através de representações estereotipadas nos filmes de Hollywood que antigamente não costumava nem mesmo ter um ator asiático para o papel e sim um ator branco fazendo o que é comumente conhecido como "Yellow Face" que consiste em uma forma de maquiagem teatral usada por artistas brancos para representar uma pessoa com etnia Asiática e é semelhante à prática de blackface com afro-descendentes, Um exemplo é Breakfast at Tiffany's (Axelrod, 1961), com Audrey Hepburn, no qual o vizinho Mr. Yunioshi, possuía dentes tortos e sotaque típico, parodia um japonês e foi interpretado pelo ator caucasiano estadunidense Mickey Rooney.

Nesse contexto, é possível perceber, por exemplo, que o sucesso dos filmes de Bruce Lee, além da popularização de filmes de artes marciais contribuíram para o senso comum de que, hipoteticamente, "Todos os asiáticos sabem artes marciais".

Esses padrões se se estendem além do ocidente e possuem influência nos doramas, mostrando que apesar de esses serem geralmente direcionados para o público japonês, eles também apresentam uma representação "padrão" que se estende desde o comportamento de seus protagonistas, até a forma que é apresentada suas habitações.

Os personagens de muitos doramas costumam representar algum tipo de estereótipo que pode ser visto como uma maneira de levar a público a compreender através de recursos visuais e de maneira rápida o contexto daquela história. Apesar disso, a maneira de representar os asiáticos na cultura pop japonesa cresceu com a facilidade de acesso mundial à conteúdo desse grupo nas últimas décadas, passando a ser representada de maneira menos ancestral e mais descontraída.

\section{Crescimento recente dos Serviços de Streaming}

É possível perceber que a maneira que o ocidente enxerga a sociedade oriental tem sido modificada nos últimos anos deixando de ser ligada apenas à uma cultura tradicional e adquirindo uma representação mais divertida e colorida, associada à indústria do entretenimento.

Em meados dos anos 1990 o anime e o mangá passaram a ser amplamente divulgados no ocidente, o que atraiu a atenção para a cultura pop japonesa, porém as telenovelas ainda não eram amplamente conhecidas fora de seu país de origem.

Essa realidade mudou com o crescimento dos serviços de Streaming o que facilitou o acesso da população ocidental ao conteúdo audiovisual asiático. Nos últimos anos, sites como o Youtube, Netflix e Dailymotion facilitaram o acesso da população mundial à conteúdos provenientes de praticamente toda parte do mundo, desprendendo as pessoas da programação da TV e permitindo que elas tenham acesso a diversos conteúdos a qualquer momento. Além desses sites de distribuição de conteúdo audiovisual, há também disponíveis na internet sites e aplicativos específicos para aqueles que buscam conteúdo oriental, tais como o site $V_{i k i^{10}}$ e o aplicativo Crunchroll ${ }^{11}$.

Esse avanço também gerou comunidades de fãs da cultura pop japonesa, conhecidos popularmente como Otakus $^{12}$, fazendo com que aqueles que possuem familiaridade dos idiomas dessas telenovelas estejam dispostos a ajudar aqueles que não detêm tal conhecimento através de uma técnica conhecida popularmente com fansub. No artigo "Hana Yori Dango: O Fenômeno do Dorama no Brasil" a na época graduanda em Comunicação Social com Habilitação em Jornalismo da Faculdade de Comunicação, Universidade Federal da Bahia Barbara Lisiak de Franca comenta as "fansubs" através da citação:

\footnotetext{
9 Tradução disponível em: https://www.jornaltornado.pt/hollywood-a-maquina-de-refletir-preconceitos-emanipular-mentes/. Acesso: 13 jun. 2019

10 Disponível em: https://www.viki.com/?locale=pt. Acesso: 30 abr. 2019.

${ }^{11}$ Disponível em: https://www.crunchyroll.com/interstitial/android. Acesso: 30 abr. 2019.

${ }^{12}$ Nome atribuído internacionalmente à fãs de anime e mangá, porém no Japão, o termo pode se referir a um fã de qualquer coisa em excesso.
} 
"Existe toda uma rede de fãs que se dispõem a traduzir e legendar os vídeos apenas pelo prazer de divulgar o seu desenho animado preferido. Eles se encontram em fóruns e

sites especializados, montam equipes, dividem as tarefas e depois disponibilizam gratuitamente on-line" (DORE apud FRANCA, 2008 p.)

É possível notar, portanto, que a comunidade que consiste naqueles que apreciam a cultura oriental vêm crescendo junto à facilidade de acesso à conteúdos provenientes de outros países, gerando a curiosidade quanto ao estilo de vida da população desses lugares e contribuindo, devido à reprodução naturalista na cenografia do que é "real" para o entendimento dessas pessoas sobre a maneira que esses povos vêm e representam a si mesmos.

\section{Considerações Finais}

Através de doramas, é possível observar a maneira que os profissionais responsáveis por essas produções representam o povo da região retratada de maneira que a audiência japonesa compreenda as condições de vida dos personagens através de elementos visuais, utilizando a composição do interior das habitações como recursos para esse entendimento rápido.

A partir do estudo realizado para a elaboração desse artigo, torna-se evidente que maneira que a população recebe o entretenimento proveniente de outros países se modifica junto ao desenvolvimento das sociedades mundiais. Nesse contexto, os doramas japoneses ainda são de conhecimento recente no âmbito mundial, mas estão se expandindo na representação da cultura pop do Japão.

Em termos de cenário, a questão de que sua evolução acompanha o desenvolvimento da sociedade existe desde seus primórdios. No artigo "Novos caminhos para a cenografia diante da evolução tecnológica: o teatro e a realidade aumentada" (MAIA, MUNIZ, 2018, p. 4), Hortênsia Gadelha Maia $^{13}$ e Euler Sobreira Muniz ${ }^{14}$ dissertam sobre a maneira que as mudanças nas camadas sociais pós Revolução Francesa e as inovações tecnológicas pós Revolução Industrial, mudaram a relação ator-cenário. Nesse o autor afirma que: "Com a mudança do sistema de produção, ascensão e surgimento de novas camadas sociais, o público também mudou, assim como os temas e críticas que passaram a ser novos e diferentes", sendo assim possível perceber que esses acontecimentos trouxeram mudanças no cenário teatral, deixando de ser apresentado para maravilhar o público como no Barroco, e passando a ter a função de transmitir críticas e fazer a plateia pensar acerca da situação na sociedade vigente.

\footnotetext{
${ }^{13}$ Arquiteta Urbanista, Universidade Federal do Ceará - UFC, graduação sanduíche no Institut National des Sciences Appliquées de Strasbourg - INSA. Pós-Graduação em Arquitetura de Interiores, Universidade de Fortaleza - Unifor.

${ }^{14}$ Mestre em Engenharia Civil pela Universidade Federal do Ceará - UFC.
} 
Interior Design Applied to Japanese Drama Scenography

Abstract: In the cinematographic composition scenography is used to impact viewers and contribute to the atmosphere of the story. Along with factors such as narrative, costumes, among others, the scenario is thought to constitute a structuring of the characters' lifestyle. In this context, observing the Japanese doramas, it is possible to conclude that in them the visual representation of the dwellings approaches the daily life of the society in the region portrayed. The purpose of this article is to explore the relation of the character in this type of production to the space and how it can reproduce an environment that describes its personality, attributes, nationality, among other factors that make up its life.

Keywords: Design; Drama; Scenography; Character; Ambience.

\section{Referências bibliográficas}

CAMPOS, Thalita B. Doramas: cenários da cultura asiática. Autoria secundária Maria Cristina Gobbi. Iniciação Científica CESUMAR jul./dez. 2015, v. 17, n. 2, p. 173-181.

CARLOS, Giovana S. Identidade(s) no consumo da cultura pop japonesa. Juiz de Fora, 2010.

CARLOS, Giovana S. Do mangá para o dorama: a representação da irritação em nodame cantabile. R. Interamericana de Comunicação Midiática, http://www.ufsm.br/revistas E-ISSN 21754977 , v. 11, n. 21, Jan-Jun (2012).

CERETTA, Fernanda M. Novas modalidades de sitcom e o fenômeno confessional: GI3: Ficção TV e narrativa transmídia. São Paulo, 2014.

FRANCA, Barbara L. de. Hana Yori Dango: o fenômeno do dorama no brasil. Salvador, 2011.

HOWARD,Pamela. What is Scenography?. London: Routledge, 2009.

MAIA, Euler S. Novos caminhos para a cenografia diante da evolução tecnológica: o teatro e a realidade aumentada. Autoria secundária Euler Sobreira Muniz. Fortaleza, 2018.

NETO, José C. Mangá: a cultura nipônica na construção da cultura pop mundial. Fortaleza, 2012.

NUNES, SILVIA B. BOAL E BENE: contaminações para um teatro menor. São Paulo, 2004.

PELEGRINI, Christian H. O sitcom de câmera única e a serialização do estilo na comédia de TV. Crítica Cultural - Critic, Palhoça, SC, v. 10, n. 1, p. 27-44, jan./jun. 2015.

URSSI, Nelson José. A linguagem cenográfica. São Paulo, 2006.

VIEIRA, Eloy S.; ROCHA, Irla S. da Costa. A aproximação entre indústrias midiáticas e os fãs: 0 caso do DramaFever no Brasil. Autoria secundária Lilian Cristina Monteiro França. Rio de Janeiro, 2015.

XAVIER, Ismail. 0 discurso cinematográfico: a opacidade e a transparência. São Paulo, 2005. 